\title{
Modeling elephant-mediated cascading effects of water point closure
}

\author{
Jelle P. Hilbers, ${ }^{1,2,10}$ Frank van Langevelde, ${ }^{1}$ Herbert H. T. Prins, ${ }^{1,3}$ C. C. Grant, ${ }^{4}$ Mike J. S. Peel,${ }^{5}$ \\ Michael B. Coughenour, ${ }^{6}$ Henrik J. de Knegt,,${ }^{1,7}$ Rob Slotow, ${ }^{3}$ Izak P. J. Smit,${ }^{4}$ Greg A. Kiker, ${ }^{8,9}$ \\ AND Willem F. DE Boer ${ }^{1}$ \\ ${ }^{1}$ Resource Ecology Group, Wageningen University, Droevendaalsesteeg 3a, 6708 PB Wageningen, Netherlands \\ ${ }^{2}$ Department of Environmental Science, Institute for Wetland and Water Research, Faculty of Science, Radboud University Nijmegen, \\ P.O. Box 9010, 6500 GL Nijmegen, Netherlands \\ ${ }^{3}$ Amarula Elephant Research Program, School of Life Sciences, University of KwaZulu-Natal, Westville Campus, \\ Durban 4000 South Africa \\ ${ }^{4}$ Scientific Services, Kruger National Park, Private Bag X402, Skukuza 1350 South Africa \\ ${ }^{5}$ ARC-Animal Production Institute, P.O. Box 7063, Nelspruit 1206 South Africa \\ ${ }^{6}$ Natural Resource Ecology Laboratory, Colorado State University, Fort Collins, Colorado 80523-1499 USA \\ ${ }^{7}$ Department of Biosciences, University of Helsinki, P.O. Box 65 (Viikinkaari 1), FI-00014 Helsinki, Finland \\ ${ }^{8}$ Department of Agricultural and Biological Engineering, Institute of Food and Agricultural Sciences, University of Florida, Gainesville, \\ Florida 32611-0570 USA \\ ${ }^{9}$ School of Mathematics, Statistics, and Computer Science, University of KwaZulu-Natal, Pietermaritzburg 3200 South Africa
}

\begin{abstract}
Wildlife management to reduce the impact of wildlife on their habitat can be done in several ways, among which removing animals (by either culling or translocation) is most often used. There are, however, alternative ways to control wildlife densities, such as opening or closing water points. The effects of these alternatives are poorly studied. In this paper, we focus on manipulating large herbivores through the closure of water points (WPs). Removal of artificial WPs has been suggested in order to change the distribution of African elephants, which occur in high densities in national parks in Southern Africa and are thought to have a destructive effect on the vegetation. Here, we modeled the long-term effects of different scenarios of WP closure on the spatial distribution of elephants, and consequential effects on the vegetation and other herbivores in Kruger National Park, South Africa. Using a dynamic ecosystem model, SAVANNA, scenarios were evaluated that varied in availability of artificial WPs; levels of natural water; and elephant densities. Our modeling results showed that elephants can indirectly negatively affect the distributions of meso-mixed feeders, meso-browsers, and some meso-grazers under wet conditions. The closure of artificial WPs hardly had any effect during these natural wet conditions. Under dry conditions, the spatial distribution of both elephant bulls and cows changed when the availability of artificial water was severely reduced in the model. These changes in spatial distribution triggered changes in the spatial availability of woody biomass over the simulation period of 80 years, and this led to changes in the rest of the herbivore community, resulting in increased densities of all herbivores, except for giraffe and steenbok, in areas close to rivers. The spatial distributions of elephant bulls and cows showed to be less affected by the closure of WPs than most of the other herbivore species. Our study contributes to ecologically informed decisions in wildlife management. The results from this modeling exercise imply that long-term effects of this intervention strategy should always be investigated at an ecosystem scale.
\end{abstract}

Key words: animal densities; Kruger National Park; Loxodonta africana; meso-herbivores; savanna ecosystems; spatial distribution; surface water.

\section{INTRODUCTION}

Several intervention strategies exist for wildlife management to reduce the impact of wildlife species on their habitat (Wright 1999). Direct management actions, such as culling, contraception, and translocation generally aim at reducing animal numbers, which should lower the intensity of resource use and, ultimately, the impact on other species (Balfour et al. 2007, Van Aarde et al. 2008). Although the removal of animals via translocation or culling is most commonly

Manuscript received 14 February 2014; revised 7 May 2014; accepted 18 July 2014. Corresponding editor: T. G. O'Brien.

${ }^{10}$ E-mail: j.hilbers@science.ru.nl used, these strategies are often controversial (Van Aarde and Jackson 2007, Smith et al. 2010). There are, however, alternative ways to control wildlife impacts, through fencing or the manipulation of surface water. These management actions aim to indirectly influence the spatial distribution of animals, so that intensity of resource use and the impact on other species locally decreases. The effects of these alternatives are, however, poorly studied (Balfour et al. 2007, Van Aarde et al. 2008). An ideal study subject to investigate the impact of surface water manipulation is the African elephant (Loxodonta africana; Biggs et al. 2008). African elephants are considered to be ecosystem engineers, as they largely change the physical environment in which they 
live and have a potential cascading effect on other species (Valeix et al. 2011, Lagendijk et al. 2012). Their increasing densities in national parks in Southern Africa have become a concern for park management (Harris et al. 2008, Smit and Ferreira 2010), as elephants debark, push over, and uproot trees and break tree branches and stems, thereby changing the structure of the vegetation (Kerley et al. 2008, Kohi et al. 2011). By influencing vegetation structure, biomass, and composition, elephants may affect meso-browsers (Fritz et al. 2002, Lagendijk et al. 2012), such as steenbok (Raphicerus campestris) and kudu (Tragelaphus strepsiceros), mesomixed feeders (Fritz et al. 2002, Lagendijk et al. 2012), like impala (Aepyceros melampus), and meso-grazers (de Boer and Prins 1990, Van De Koppel and Prins 1998), including buffalo (Syncerus caffer).

To manipulate the impact of elephants on their habitat, the construction or closure of artificial water points (WPs) is considered to be a suitable strategy (Smit et al. 2007a, Van Aarde et al. 2008), as surface water is a key driver in elephant distribution and population dynamics (Chamaillé-Jammes et al. 2007a, De Knegt et al. 2011). Due to the construction of WPs, elephants may range into areas that were previously inaccessible to them or spend longer periods in areas where they would only have ranged when natural water was available (Loarie et al. 2009, Smit and Grant 2009); elephant home range sizes may decrease in both the dry and the wet season (de Beer and Van Aarde 2008, Van Aarde et al. 2008); and elephant densities may increase locally, since young animals are, predominately, susceptible to droughts (Chamaillé-Jammes et al. 2007b, Van Aarde and Jackson 2007).

The closure of WPs is, therefore, expected to influence the densities and distribution of elephants, and thus, their effects on the vegetation, and, as such, is one of the tools that can be used to manage elephant impact (Van Aarde et al. 2008, Smit and Grant 2009). In the Kruger National Park (KNP), South Africa, WPs have been constructed, relocated, and closed for numerous reasons over the past 100 years. In the late 1980s, the number of WPs peaked, but more than half of the WPs were closed in the following decades. This, however, did not result in the expected effects, as, for example, the numbers of rare antelopes continued to decline (Smit et al. 2007a) and elephant numbers continued to increase (Smit 2013). At present, KNP management is planning to permanently or temporarily close more of the currently remaining WPs to mimic a more natural surface-water distribution, allowing vegetation and animal distribution patterns to recover and to increase heterogeneity (Smit 2013). However, the anticipated system-wide effects of the closure of these WPs on elephants are debated (Chamaillé-Jammes et al. 2007a, Smit et al. 2007b). Successful management requires an understanding of the large-scale effects of closing WPs (Loarie et al. 2009), not only the effects on elephants, but also on other large herbivore species and vegetation (Smit et al. 2007b,
Mwakiwa et al. 2012). Here, we report on the possible long-term effects of different scenarios of WP-closure on the spatial distribution of elephants, and the cascading effects on the vegetation and other browser and grazer species. Using a dynamic ecosystem model, SAVANNA (Coughenour 1993), several scenarios were evaluated that varied in availability and spatial arrangement of artificial WPs; levels of natural water availability to investigate the effects of wet and dry years, i.e., the effect of drought; and population sizes of elephants to examine potential cascading effects.

\section{Methods \\ Study area}

This modeling exercise simulated the effects of surface water manipulation and elephant densities in the Kruger National Park (KNP), South Africa (Fig. 1). The park covers an area of around $20000 \mathrm{~km}^{2}$ with annual rainfall varying between $300 \mathrm{~mm}$ and $700 \mathrm{~mm}$. Five perennial rivers cross the park from west to east, and 14 ephemeral rivers contain surface water only during the wet season (Du Toit et al. 2003).

\section{Model}

SAVANNA is a series of interconnected Fortran computer programs that simulates the various processes at work in arid and semiarid ecosystems, including, for example, nutrient cycling, hydrology, plant biomass production, and ungulate spatial dynamics (Coughenour 1993, Boone and Hobbs 2004). The initial development of SAVANNA began in 1985, and was applied to the Turkana District of Kenya (Coughenour 1985). The model has been updated and commonly used in savanna ecosystems since (Ludwig et al. 2001, Boone et al. 2002, 2005, Thornton et al. 2004, Boone 2007), including in KNP (Kiker 1998). The model is spatially explicit in that landscapes are covered by a grid of cells and ecological processes are modeled per cell. SAVANNA reads spatial data that include soil type, distance to water, vegetation type, vegetation cover, elevation, and slope (Fig. 1; Boone and Hobbs 2004). Initial vegetation biomass density per cell was calculated by combining these imagery- and field-based maps on tree, shrub, and herbaceous cover (Fig. 1; Kiker 1998, De Knegt et al. 2011), vegetation type, mean tree, shrub, and herbaceous root biomass, height data, and on an initial sizeclass distribution for trees. Precipitation and more detailed information about radiation, $\mathrm{CO}_{2}$ concentration, wind speed, minimum and maximum temperature, and humidity (Coughenour 1993, Boone 2007) were obtained from a series of weather stations. Using weather input and soil properties, the model determines water and nutrient availability to plants for each cell. These, together with light availability, define the products of photosynthesis that are calculated for the plant functional groups using process-based methods, and are allocated to leaves, stems, and roots using plant allometries, providing plant primary production esti- 

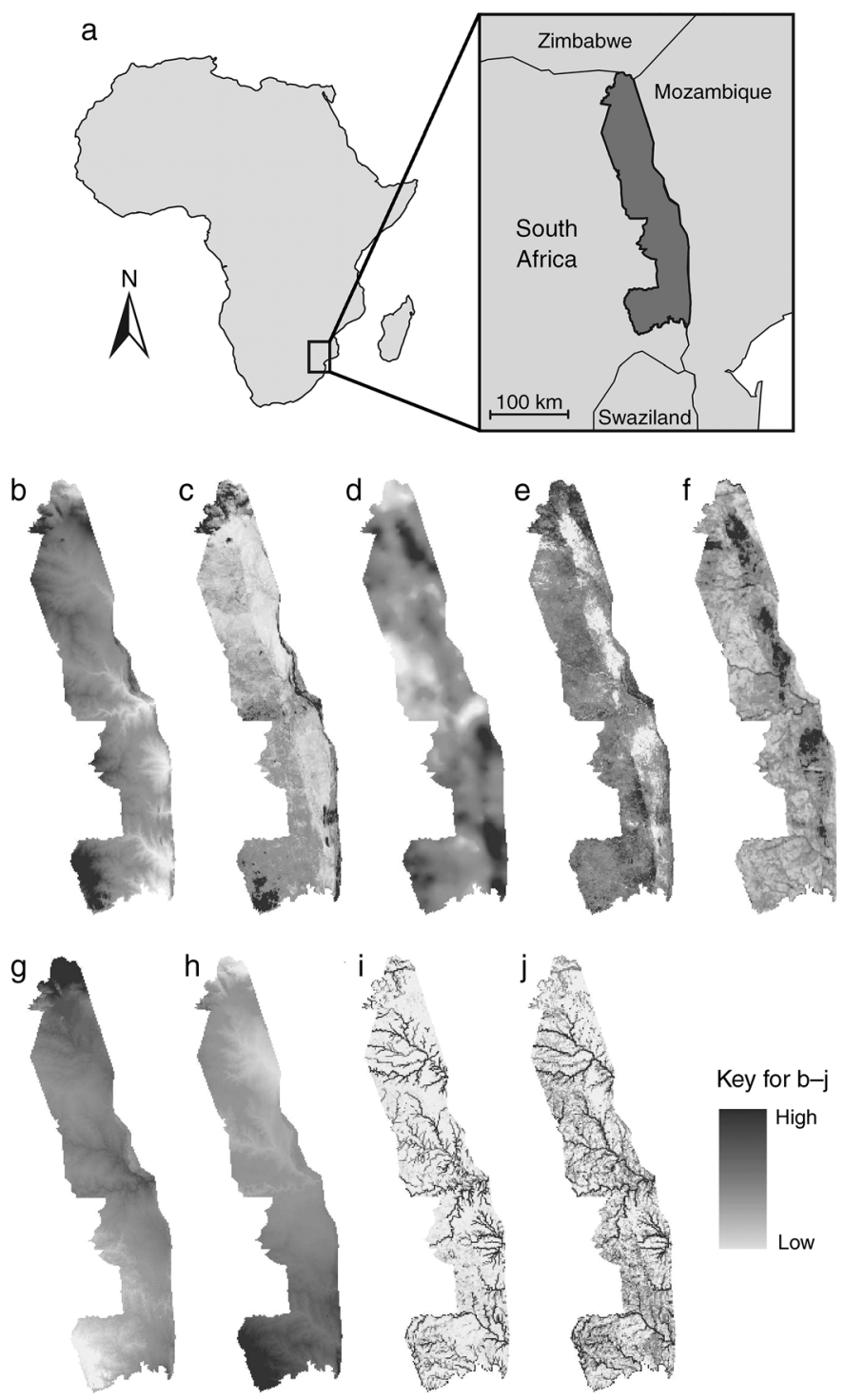

Key for b-j
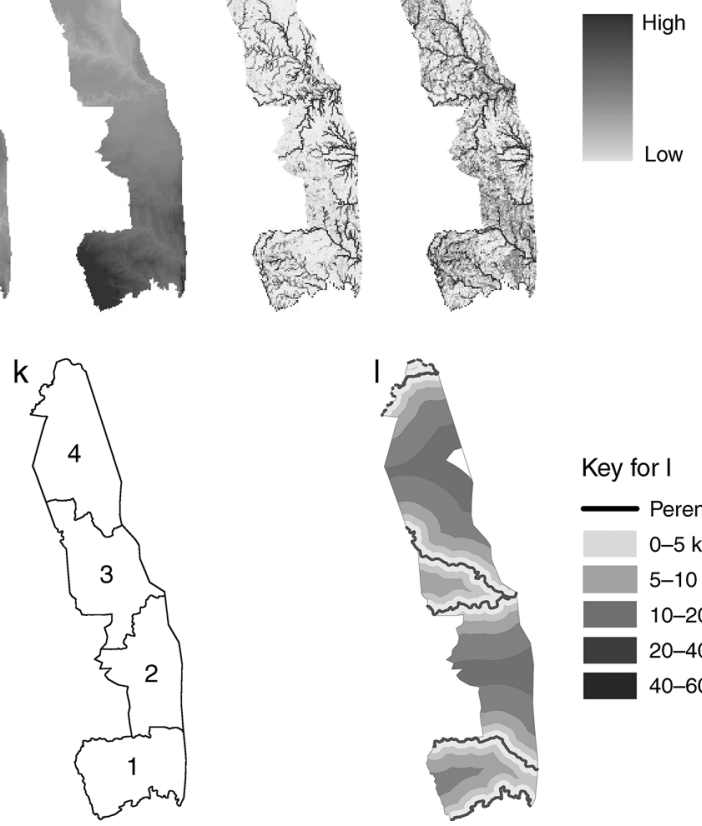

Key for I
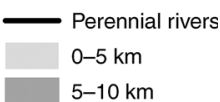

$10-20 \mathrm{~km}$

20-40 km

40-60 km

FIG. 1. Maps of Kruger National Park (KNP) and environmental variables. Maps depict (a) location of KNP, (b) elevation, (c) slope, (d) herbaceous biomass, (e) woody cover, (f) vegetation heterogeneity, (g) mean annual temperature, (h) mean annual rainfall, (i) water occurrence, (j) water permanency, (k) location of the four regions used in this model study, and (l) areas that were analyzed from particular distance to the perennial rivers. The variables are mapped at a resolution of $1 \mathrm{~km}^{2}$ (modified from De Knegt et al. 2011). 
mates. Plant primary production, together with herbivory, determines plant-group population dynamics, in which plant establishment, (re)growth, and mortality is modeled. Animal functional groups are distributed over the landscape per individual, based upon a habitat suitability index that is calculated for each cell in the landscape and each animal functional group. The habitat suitability index is determined by forage quality and quantity, slope, elevation, cover, water availability, and the density of herbivores. Animals graze and/or browse upon the available vegetation, depending on the distribution and abundance of available vegetation, dietary preferences, and consumption rates. The effect of forage abundance on food intake rate by the herbivores is represented as a Type II functional response, where food intake rates for each herbivore species are calculated using the maximum intake rate of each plant type, the current condition of an animal, and forage quality, i.e., digestibility. Additional impacts of herbivores on plants via wasting, trampling, and uprooting are included as well. Summaries of the status of vegetation, herbivores, and climate are produced at monthly intervals (Coughenour 1993, Boone et al. 2002, Boone and Hobbs 2004, Boone 2007). For more detail about SAVANNA, see Coughenour (1993), Ellis and Coughenour (1998), and Appendix A for a general relational diagram describing the model. The SAVANNA parameter values used in this study, based on previous SAVANNA applications, scientific literature, expert knowledge, and analyses of the GPS data of collared elephants, are also given in Appendix A.

Previous versions of SAVANNA (Kiker 1998) did not distinguish male from female elephants, although important differences exist between males and females. Bulls have lower feeding requirements in terms of forage quality, have a wider habitat tolerance, and increased mobility (Smit et al. 2007c). Hence, elephant cow groups are found closer to rivers in savanna ecosystems in Southern Africa compared to bull groups, where they find higher quality forage (Stokke and Du Toit 2002, Smit et al. 2007c). This leads to differences in impact on vegetation near rivers and, consequently, one can expect that bulls and cows have different potential cascading effects on other large herbivore species (Stokke and Du Toit 2002, Smit et al. 2007c, Harris et al. 2008). We, therefore, included elephant cows and bulls separately in SAVANNA.

Moreover, the model ignored that browsing occurs, in reality, at different heights and elephant browsing probably influences browser species differently, e.g., by pushing over trees or by browsing at certain heights (Greyling 2004). Therefore, we included different height classes of trees in the model. The size-class distribution of the woody species was changed for fineleaved trees and marula (Sclerocarya birrea) to 0-1, 1$2,2-3,3-6,6-11.56$, and $11.56-17 \mathrm{~m}$; for broad leaved trees to $0-1,1-2,2-3,3-4,4-5$, and 5-6 m; and for mopane (Colophospermum mopane) to $0-1,1-2,2-3$,
3-4, 4-6, and 6-7 m. All shrubs were assigned to the class $0-1 \mathrm{~m}$.

Next to grazer (buffalo, wildebeest, roan, and zebra) and mixed-feeder species (impala and elephant cows and bulls), four browser species were incorporated in the model to investigate the cascading effects of WP management on other browser species. Browsing heights were divided into four classes (0-100, 101-200, 201-300, and $>300 \mathrm{~cm}$ ) from which a single browser species was selected to represent browsing in a particular height class (Appendix A). We included steenbok, bushbuck (Tragelaphus sylvaticus), kudu, and giraffe (Giraffa camelopardalis) in the model. Feeding height preferences of browsers and mixed-feeders were obtained from other studies (Du Toit 1990, Haschick and Kerley 1996, Makhabu 2005, Cameron and Du Toit 2007). The KNP population sizes of the herbivore species were kept constant at numbers obtained from the 2010 census data, in which elephant individuals observed in cow groups were assumed to be female (Smit et al. 2007c; Appendix B).

\section{Water point management scenarios}

We modeled four hypothetical WP management scenarios based on past, current, and future WP locations and water management policies in KNP (Fig. 2). We included 705 individual WPs in the model and assumed that these were all accessible to wildlife. Furthermore, we assumed that all WPs contain water during the wet season, and that only boreholes, pipeline troughs, dams with a borehole, and large dams contain water during the dry season (thus excluding small and moderate size dams). The scenarios were as follows:

1) Wide-scale water provision scenario where all 705 WPs were open, of which 616 WPs contained water during the dry season (Open).

2) Intermediate water provision scenario where 349 WPs out of 705 were open. During the dry season, 289 WPs were assumed to contain water. Under the very dry natural water scenario, WPs that are standby were assumed to be (temporary) reopened so that, in total, 351 WPs were open, of which 291 were assumed to contain water during the dry season (Intermediate).

3) Reduced water provision scenario where 224 WPs were open. During the dry season, 200 WPs were assumed to contain water. In the very dry natural water scenario, 247 WPs were open, of which 223 were assumed to contain water during the dry season (Reduced).

4) No water provision, where all 705 WPs were closed so that only natural water occurred in the area (Closed).

\section{Natural water availability}

To define four natural water scenarios, we used data on the permanency of water in KNP during the dry season, calculated from observations of water availabil- 


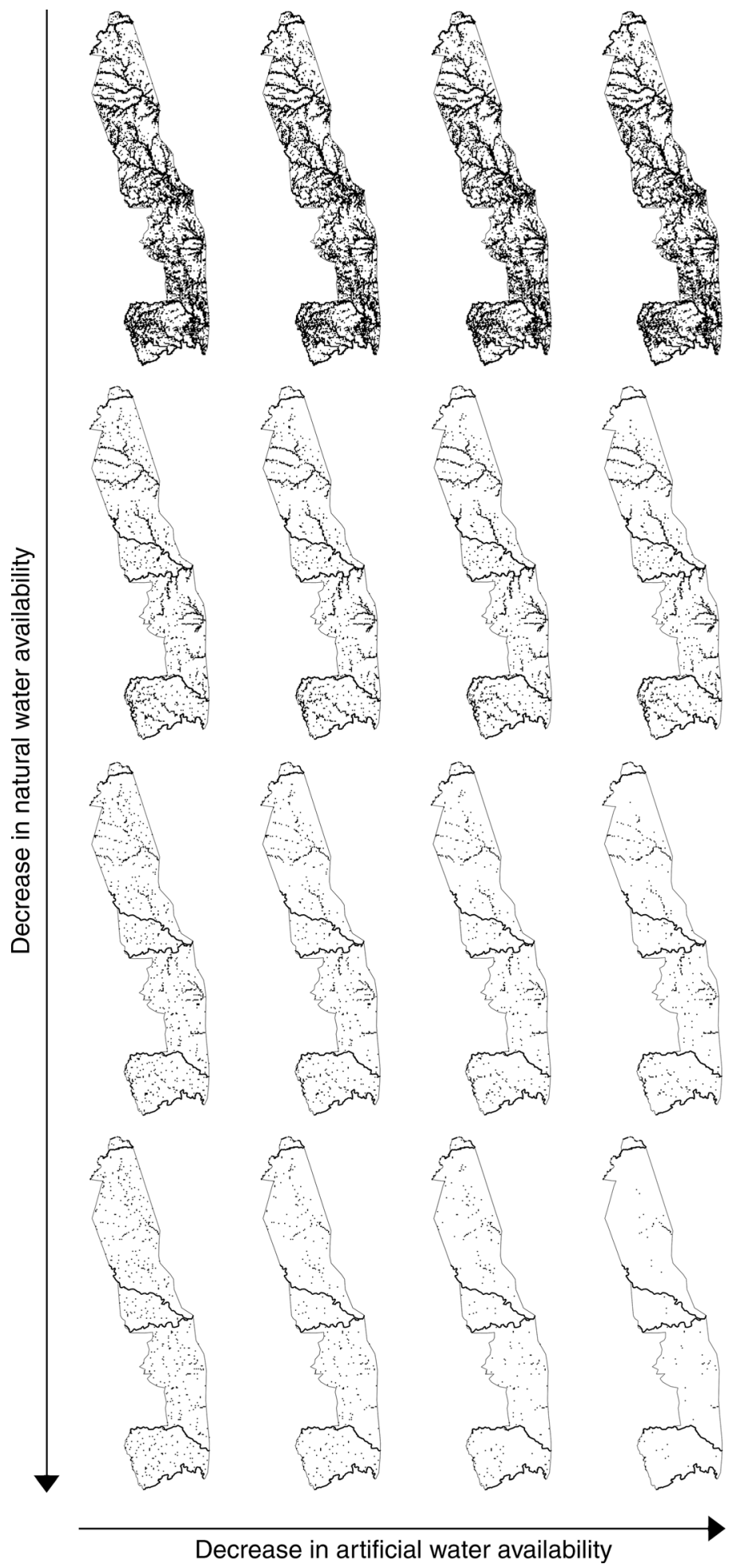

FIG. 2. Graphical representation of the water scenarios. From left to right, there is a decrease in artificial water availability: opening all water points (WPs) on the left, intermediate WP scenario, reduced WP scenario, and closing all WPs on the right. From top to bottom, there is a decrease in natural water availability: very wet at the top, intermediately wet, intermediately dry, and very dry at the bottom. 
ity during the megaherbivore aerial census from 19812001 ( $n=17$ years, excluding years 1985 and 1994-1996, for which no census data was available) within a $1-\mathrm{km}$ grid-square (Fig. 2).

We depicted scenarios wherein there was water present in very wet years where we included all grid cells where water has been observed during at least three out of the 17 years (33\% of $1-\mathrm{km}$ grid cells contained water); in intermediately wet years with grid cells where water has been observed during at least eight out of the 17 years ( $9 \%$ with water); in intermediately dry years with grid cells where water has been observed during at least 12 out of the 17 years (5\% with water); in very dry years with grid cells where water has been observed during at least 15 out of the 17 years ( $3 \%$ with water). The five perennial rivers were assumed to hold water for the entire year in all scenarios.

\section{Elephant population sizes: simulating different elephant numbers}

To investigate the impact of elephant population size on other system variables, we applied three elephant population sizes (Appendix B): present (2010) elephant numbers, i.e., 13749 elephants (Current); present (2010) elephant numbers $-50 \%$, i.e., 6872 elephants (Low); and present (2010) elephant numbers $+50 \%$, i.e., 20626 elephants (High).

\section{Simulations}

The model was run over 80 years with weekly time steps, using weather input data from 1992-2012. To that end, four random weather data sequences of 20 years were created by random permutation of the original data on a yearly basis so that seasonal variability in vegetation growth was maintained. To obtain distanceto-water maps with a grid cell resolution of $25 \mathrm{~km}^{2}$, which are needed as model input for each scenario (see also, Coughenour 1993), the Euclidean distance was calculated to each WP and $1-\mathrm{km}$ grid-square that contained natural water; the resulting two maps of a $1-\mathrm{km}^{2}$ resolution were spatially combined by taking the minimum distance-to-water cell value; and the local average was calculated for the cells within the $25-\mathrm{km}^{2}$ grid-squares. Redistribution of herbivores over time was limited to regions within KNP (Fig. 1k).

In total, 60 scenarios were run and 57600 maps per animal species or plant group with a $25 \mathrm{~km}^{2}$ grid cell resolution were created. Results of the first 60 years were omitted, since the model needed 40-60 years to equilibrate, given the initial conditions that these were based on different data sources collected in different years and might have led to artificial fluctuations in the starting phase. To summarize the results, the average plant biomass $\left(\mathrm{g} / \mathrm{m}^{2}\right)$ available for herbivores, i.e., leaves, current annual growth (CAG), and fine branches, were calculated, together with the mean animal densities (number per grid cell) at distances of $0-5,5-10,10-20$, 20-40, and 40-60 km from the five major rivers in KNP
(Fig. 11). Standardized regression coefficients were derived using linear regression on plant biomass and animal densities as an indication of the effect size of the one variable on the other (and vice versa). To estimate the effect sizes of the different scenarios, we compared each scenario with the intermediate water provision situation (Intermediate) in Water point management scenarios. Therefore, the natural logarithms of the ratio in percentages between the intermediate water provision scenario and the other WP scenarios, and between the current elephant densities and other elephant densities, were calculated.

\section{Results \\ Impact of different water scenarios}

The effects on the average plant biomass $\left(\mathrm{g} / \mathrm{m}^{2}\right)$ and animal densities (number per grid cell) are summarized in Fig. 3.

Both elephant bulls and cows showed overlapping spatial distributions and their densities were positively correlated (standardized regression coefficient $=0.95, P$ $<0.001, n=240$ ). The model generated high elephant densities near rivers, even when natural and artificial water was abundant. Food limitation and other habitat constraints, such as low woody cover in areas further away from rivers, explained why elephants were more abundant closer to rivers. However, elephant bulls were distributed more evenly across KNP, and were relatively more present further away from rivers than were elephant cows. The closure of WPs in the intermediately dry and very dry scenarios led to lower elephant densities in areas further away from rivers and higher densities near rivers. This effect was larger for elephant cows than for bulls.

Woody biomass was positively correlated among all size classes (Appendix C). The majority of the modeled woody biomass of all size classes was found within 40 $\mathrm{km}$ of rivers. The biomass of all size classes increased at distances larger than $5 \mathrm{~km}$ from rivers up to $40 \mathrm{~km}$, when natural water became sparser. Modeling a decreasing availability of artificial water under naturally dry conditions decreased the biomass of all size classes, apart from the $0-1 \mathrm{~m}$ size class, at distances close to rivers, whereas biomass increased at distances farthest away from rivers. Woody biomass in the $0-1 \mathrm{~m}$ size class increased when WPs were closed, especially at distances further away from rivers $(>10 \mathrm{~km})$, caused by an increase in shrub biomass.

The average grass biomass clearly increased with increasing distance from perennial rivers, probably due to the higher tree cover near rivers, and the competition between these plant groups (Appendix C). The grass biomass did not change much among the natural water availability scenarios. Grass biomass also showed limited effects due to the closure of WPs. It slightly decreased near rivers and slightly increased further away from rivers when WPs were closed, under dry conditions. The fraction of the primary production of grass 


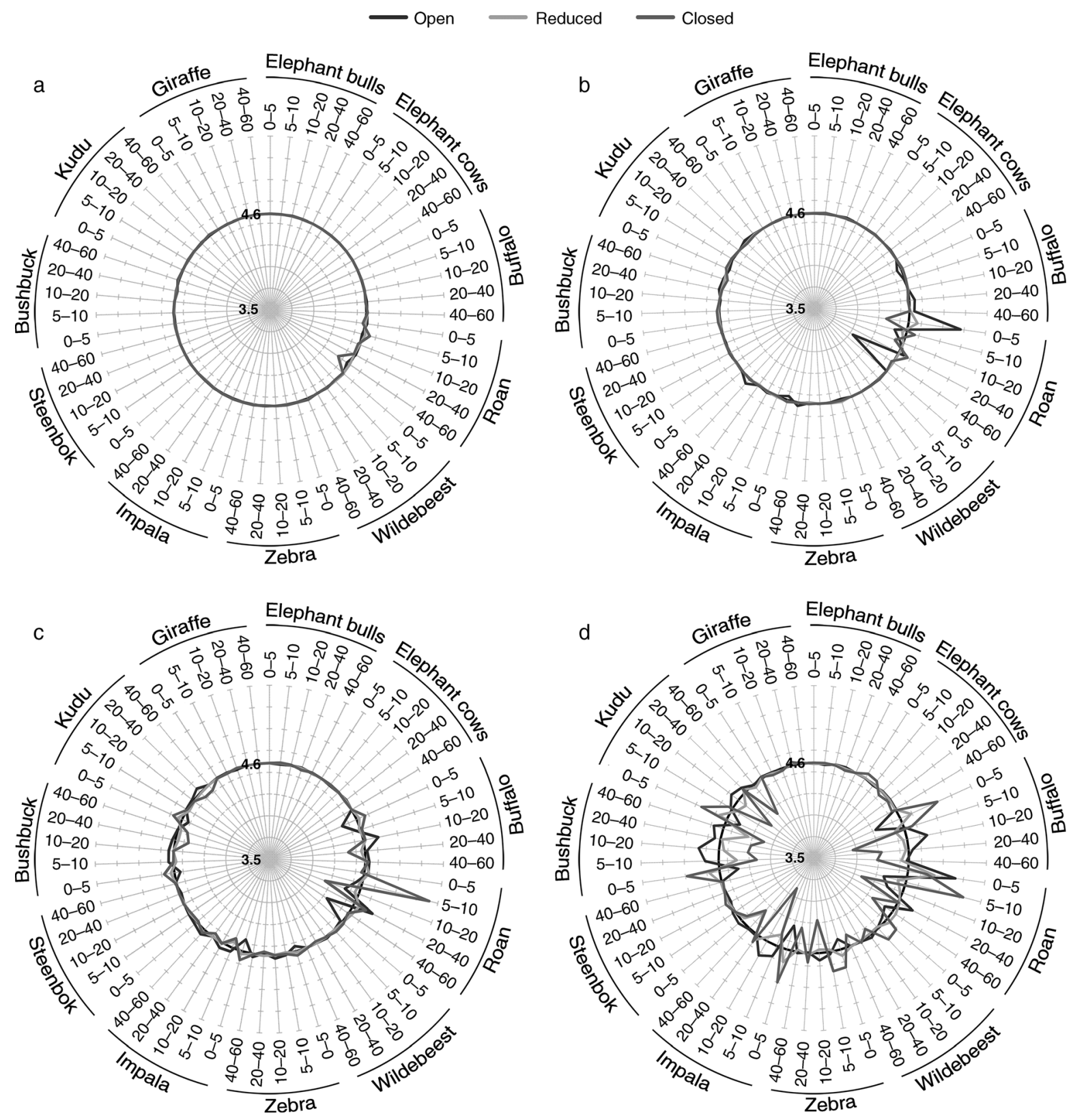

FIG. 3. The change in spatial distributions at distances of $0-5,5-10,10-20,20-40$, and $40-60 \mathrm{~km}$ to perennial rivers in clockwise direction of $(\mathrm{a}-\mathrm{d})$ animal species and $(\mathrm{e}-\mathrm{h})$ plant groups (grass biomass, woody biomass in five size classes) under current elephant densities for the (a,e) very wet, $(b, f)$ intermediately wet, $(c, g)$ intermediately dry, and $(d, h)$ very dry scenarios. Differences were standardized by taking the natural logarithm of the percentage of change of the open, reduced, and closed WP scenario, relative to the intermediate WP scenario. See Methods: Water point management scenarios for definitions of these scenarios.

biomass consumed by herbivores ranged from $9.3 \%$ to $13.3 \%$ (Table 1), indicating that the influence of consumption on grass biomass is only moderate, which could explain why no effects of changing natural and artificial water availability were observed.

Meso-grazers were spread out across KNP, but zebra and, especially, wildebeest reached higher densities far from perennial rivers, buffalo closer to rivers, and roan at intermediate distances from rivers. Under intermedi- ately dry scenarios, wildebeest and zebra densities did not change when WPs were closed, and forage limitation determined their spatial distribution. Areas near rivers were avoided by zebra due to competition with buffalo. Densities of buffalo and roan were positively correlated, while both correlated negatively with wildebeest, and buffalo correlated negatively with zebra. Zebra and wildebeest densities were positively correlated (Appendix C). Furthermore, by performing simulations with 


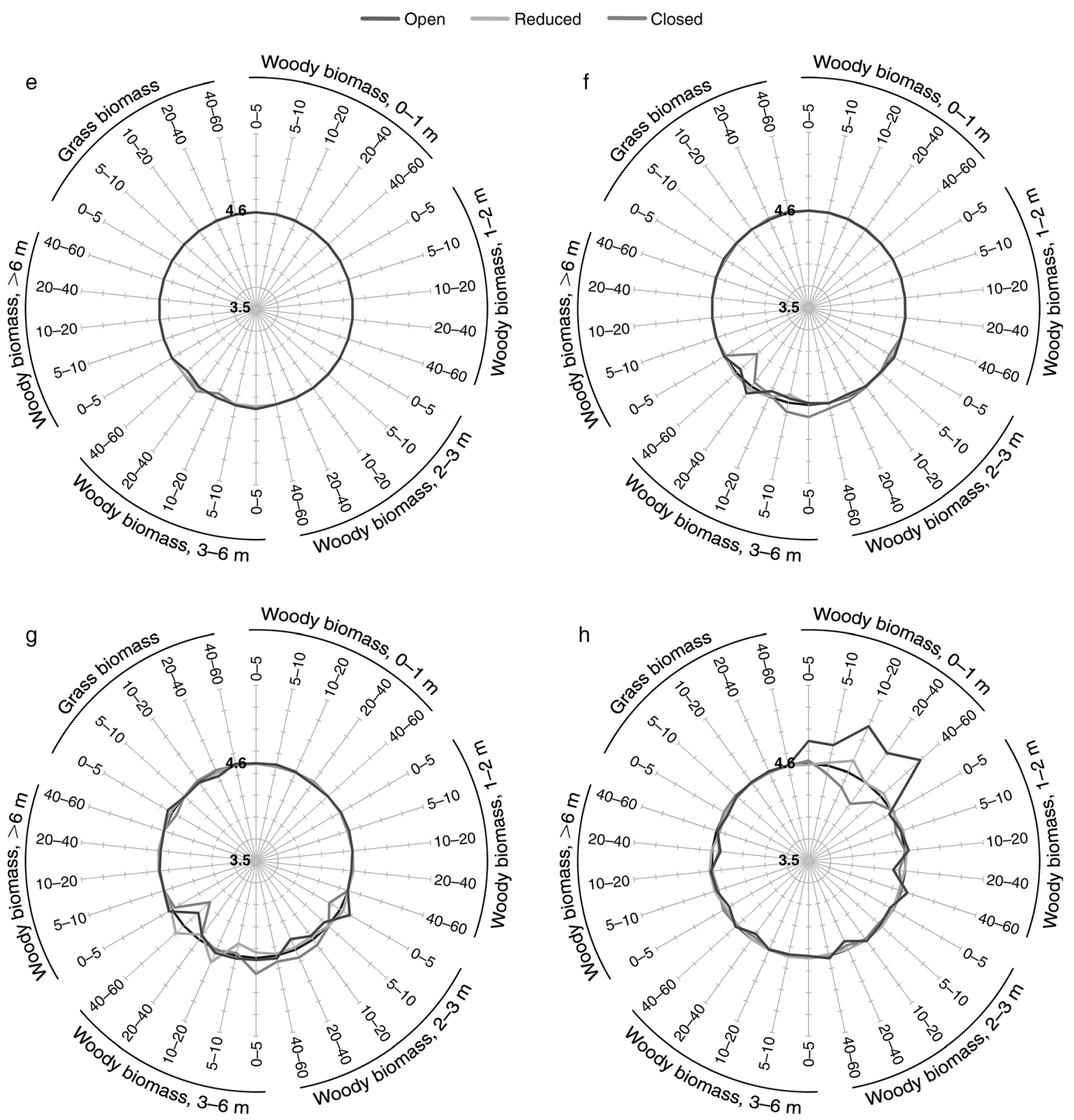

FIG. 3. Continued.

and without buffalo and with only wildebeest as animal species within the model, it was found that wildebeest were facilitated by both buffalo and zebra, since these species foraged on tall grasses, increasing the accessibility and availability of edible shorter grasses for wildebeest (Appendix D).

Roan and buffalo densities differed in the intermediately dry scenario, showing a movement toward rivers when artificial water became sparser, suggesting a stronger water-limitation of these species. However, for roan, this movement toward rivers was not consistent. Roan numbers were low, which means that this species' spatial distribution was heavily influenced by individual redistributions, explaining the changes in spatial distribution. All meso-grazers, but mainly buffalo, roan, and zebra, moved toward rivers in the very dry scenario (Fig. 3), and their densities in areas farthest away from rivers consequently decreased due to water limitation.

The distribution of impala varied among both natural and artificial water availability. Under very wet conditions, impala were not influenced by closing WPs and were mainly present in areas farthest away from rivers. Hence, the closure of WPs did not affect the distribution of impala when natural surface water was not limiting. This was also true for the intermediately wet scenario, 
TABLE 1. The influence of elephant density on grass and woody dry mass annual primary production (APP), biomass, and dry mass yearly consumption for the two most extreme natural and artificial water availability scenarios.

\begin{tabular}{|c|c|c|c|c|c|c|c|c|}
\hline \multirow[b]{3}{*}{ Scenario and density } & \multicolumn{4}{|c|}{ Grass } & \multicolumn{4}{|c|}{ Woody } \\
\hline & \multirow{2}{*}{$\begin{array}{l}\text { Dry mass } \\
\text { APP }\end{array}$} & \multirow{2}{*}{$\begin{array}{l}\text { Average } \\
\text { biomass }\end{array}$} & \multicolumn{2}{|c|}{$\begin{array}{l}\text { Dry mass yearly } \\
\text { consumption }\end{array}$} & \multirow{2}{*}{$\begin{array}{l}\text { Dry mass } \\
\text { APP }\end{array}$} & \multirow{2}{*}{$\begin{array}{l}\text { Average } \\
\text { biomass }\end{array}$} & \multicolumn{2}{|c|}{$\begin{array}{l}\text { Dry mass yearly } \\
\text { consumption }\end{array}$} \\
\hline & & & Total & By elephants & & & Total & By elephants \\
\hline \multicolumn{9}{|l|}{ Very dry (closed) } \\
\hline Low & 318.53 & 339.40 & $31.44(9.26 \%)$ & $6.47(1.91 \%)$ & 18.93 & 19.64 & $1.74(8.86 \%)$ & $0.51(2.60 \%)$ \\
\hline Current & 318.31 & 334.21 & $37.66(11.27 \%)$ & $12.84(3.84 \%)$ & 18.11 & 18.94 & $2.02(10.67 \%)$ & $0.80(4.22 \%)$ \\
\hline High & 318.23 & 329.70 & $43.30(13.13 \%)$ & $18.76(5.69 \%)$ & 17.86 & 19.47 & $2.21(11.35 \%)$ & $1.03(5.29 \%)$ \\
\hline \multicolumn{9}{|l|}{ Very wet (open) } \\
\hline Low & 320.52 & 341.81 & $31.69(9.27 \%)$ & $6.72(1.97 \%)$ & 16.61 & 18.71 & $1.43(7.64 \%)$ & $0.15(0.80 \%)$ \\
\hline Current & 322.05 & 338.32 & $38.42(11.36 \%)$ & $13.31(3.93 \%)$ & 15.96 & 17.73 & $1.55(8.74 \%)$ & $0.25(1.41 \%)$ \\
\hline High & 327.71 & 339.78 & $45.01(13.25 \%)$ & $19.86(5.84 \%)$ & 15.54 & 17.28 & $1.64(9.49 \%)$ & $0.38(2.20 \%)$ \\
\hline
\end{tabular}

Notes: Values are given in $\mathrm{g} / \mathrm{m}^{2}$. Values in parentheses represent the percentage of the average grass biomass in the ecosystem that is consumed in total and by elephants.

whereas, in the intermediately dry scenario, an effect of limited artificial water availability was observed. The closure of WPs moved impala to areas within $5 \mathrm{~km}$ from rivers and densities in areas further away, consequently, decreased, under very dry conditions. The closure of WPs will only have major effects on these mixed feeders when natural water availability is sparse, and, under these conditions, impala become water-limited, increasing their densities near rivers.

Meso-browsers, including giraffe, were spread across KNP, like meso-grazers. Steenbok and giraffe were never water-limited, as their densities increased with increasing distances from rivers (standardized regression coefficient $=0.98, P<0.001, n=240)$, independent of the availability of natural or artificial water sources. Bushbuck and kudu also mostly occurred further away from rivers, under wet conditions (standardized regression coefficient $=0.93, P<0.001, n=240$ ). The change in availability of artificial water did not affect any mesobrowser species under very wet and intermediately wet conditions, but in the intermediately dry and very dry scenarios, bushbuck and kudu tended to move closer to rivers when WPs were closed. On the other hand, steenbok densities decreased in areas near rivers under these conditions, and increased at distances $10-40 \mathrm{~km}$ from rivers. Giraffe were not influenced by a change in natural or artificial water availability. It appears, therefore, that forage is the major driver influencing the distributions of steenbok and giraffe.

\section{Influence of elephant density}

The spatial distribution, as well as the total available grass biomass, was hardly influenced by reducing or increasing elephant density (Fig. 4, Appendix E). However, the spatial distribution and the total available woody biomass of all size classes changed. The $2-3$ and 3-6 $\mathrm{m}$ size classes were particularly negatively influenced by elephant densities.

Although only moderate effects of elephants on grass and woody biomass were found, the spatial distributions of the mixed feeders, meso-browsers, and meso-grazers differed in reaction to the different elephant densities. The spatial distribution trends of all meso-browsers, except for giraffe, closely followed the spatial distribution and biomass changes of trees in height classes on which they prefer to browse, illustrating the potential cascading effects of elephants on meso-browsers (Fig. 4). Furthermore, when elephant densities increased, all animal species groups had lower densities close to rivers and higher densities at intermediate distances to rivers, independent of natural water availability (Fig. 4, Appendix E), indicating that elephants compete with meso-browsers, mixed feeders, and meso-grazers as they move toward the river in response to sparser water sources. Only buffalo densities increased at distances very close to rivers and, under very dry conditions, also at $5-10 \mathrm{~km}$ from rivers, suggesting either that buffalo were positively indirectly affected by elephants or that the water dependency of this animal was overriding the negative effects in terms of reduced forage availability.

\section{Discussion}

By manipulating elephant densities and the availability of natural and artificial water via model simulations, we explored the extent to which different WP closure scenarios affect the spatial distribution of elephants and investigated the concomitant cascading effects of elephants on meso-browsers, mixed feeders, and mesograzers. Our study provides new and improved insights into the large-scale and cascading effects of water management in savanna ecosystems and contributes to ecologically informed decisions in wildlife management. We found that elephants compete with all other herbivore species investigated in this study under conditions where water is not limiting, except for buffalo, on which they have a facilitative effect. This implies that elephants reduce the availability and distribution of forage for most other wildlife species. During these natural wet conditions, we found hardly any effect of the closure of artificial WPs. The spatial 
distribution of both elephant bulls and cows did change when the availability of artificial water was reduced, but only under intermediately dry and very dry conditions. These changes in spatial distribution triggered changes in the spatial availability of woody biomass over the simulation period and this led to changes in the rest of the herbivore community. Changes in the densities of a keystone species, such as elephants, can result in cascading effects that affect other trophic levels and, indeed, an entire ecosystem (e.g., Bond 1993). This has been extensively studied for predators, e.g., with the reintroduction of the wolf in Yellowstone National Park (Ripple and Beschta 2012), as well as changes in ecosystem engineers, in particular elephants, which have resulted in large cascading effects (Kerley et al. 2008). For example, the increase of browsers in the Hluhluwe Game Reserve in South Africa was ascribed to the disappearance of elephants from the region leading to bush thickening, whereas the entry of elephants in the Addo Park in South Africa has led to increasing densities of small browsers (Owen-Smith 1989). Comparing our findings with those of Ripple and Beschta (2012), we argue that the effects of water intervention measures within an ecosystem might be similar to those of predator control strategies.

The spatial distribution and availability of woody biomass at all height classes was altered when elephant densities were increased or decreased. All meso-browsers, excluding giraffe, closely tracked these changes in woody vegetation, illustrating the potential cascading effects of elephant on meso-browsers (similar to findings of Owen-Smith 1989, Lagendijk et al. 2012). Furthermore, forage limitation, rather than water limitation, was shown to be driving the spatial distributions of meso-browsers and meso-mixed feeders under the very wet and intermediately wet scenarios, indicating that elephants indirectly negatively affected their spatial distributions (comparable to findings of Redfern 2002, Redfern et al. 2003). This is partly in contrast with the results of Kohi et al. (2011), who suggested positive effects of elephants on small herbivores, but in line with the conclusions of Fritz et al. (2002), who claimed that meso-browers and meso-mixed feeders are expected to be negatively affected by elephants. Regarding mesograzers, our results indicate that zebra compete with elephants and buffalo for available forage, while wildebeest are facilitated by zebra and, to a lesser extent, by buffalo, explaining the high densities of zebra and wildebeest in areas further away from rivers with low buffalo and elephant densities (see also de Boer and Prins 1990, Van De Koppel and Prins 1998). However, zebra and wildebeest might just avoid areas near rivers because of their preference for open areas, which are located further away from rivers (Smit 2011). Regarding the interaction between buffalo and elephant, de Boer and Prins (1990) and Van De Koppel and Prins (1998) claimed that buffalo and elephant compete for the same resources, resulting in a negative correlation between the population sizes of these species. Our results showed positive regression coefficients in local densities, suggesting that either buffalo are positively indirectly affected by elephants, similar to findings of Skarpe et al. (2004), or that the water dependence of these species override the competitive effects (Smit and Grant 2009, Smit 2011).

The changes in grass and woody biomass and distribution caused by changing elephant densities were smaller than expected, whereas yearly consumption by elephants and annual primary production of both trees and grasses were comparable to rates observed in other studies (Table 1; Jacobs and Naiman 2008, Knapp et al. 2012). This lack of response can possibly be explained by two reasons. First, it was found that the percentage of total grass and wood consumption to total grass and woody biomass only moderately increased in response to an increase in elephant density (Table 1), indicating that either the KNP elephant carrying capacity might be still relatively far above the numbers used in this study or that the primary production of plants might have been simulated as too high. By running SAVANNA with gaps in woody and grass biomass, it was found that it took approximately one year before grass biomass was restored, and 10-15 years before woody biomass at the lowest heights was restored, indicating that the parameters used to simulate the primary production of plants were realistic. Animal numbers, however, were based on census data, i.e., total counts, in which possible imperfect detection might have led to an underestimation of actual numbers (Martin et al. 2010). Secondly, the exclusion of fires in this model might have led to an underestimation of the effects of changing elephant densities, since, especially, the co-occurrence of fires and herbivory has been shown to significantly influence savanna ecosystems (Dublin et al. 1990, Van Langevelde et al. 2003, Shannon et al. 2011).

The closure of WPs only changed the distribution and local densities of elephants and other species, and thus, also, their impact on the structural heterogeneity and biomass of the vegetation during drought episodes. Under very wet and intermediately wet conditions, hardly any alterations in elephant, meso-grazer, mesomixed feeder, and meso-browser spatial distributions were found when the availability of artificial water was reduced. The closure of WPs did not, in turn, lead to changes in the spatial availability of woody and grass biomass during wet episodes. Under these conditions, there is enough natural surface water available to ensure that the animals are not water-limited. Under intermediately dry and very dry conditions, shifts in the spatial distributions were clearly visible. This is comparable with findings of Smit and Grant (2009) and Mwakiwa et al. (2012), who stated that the construction or closure of WPs would affect the landscape in the KNP during periods of drought.

Both elephant bulls and cows moved closer toward natural water sources when WPs were closed, but cows 


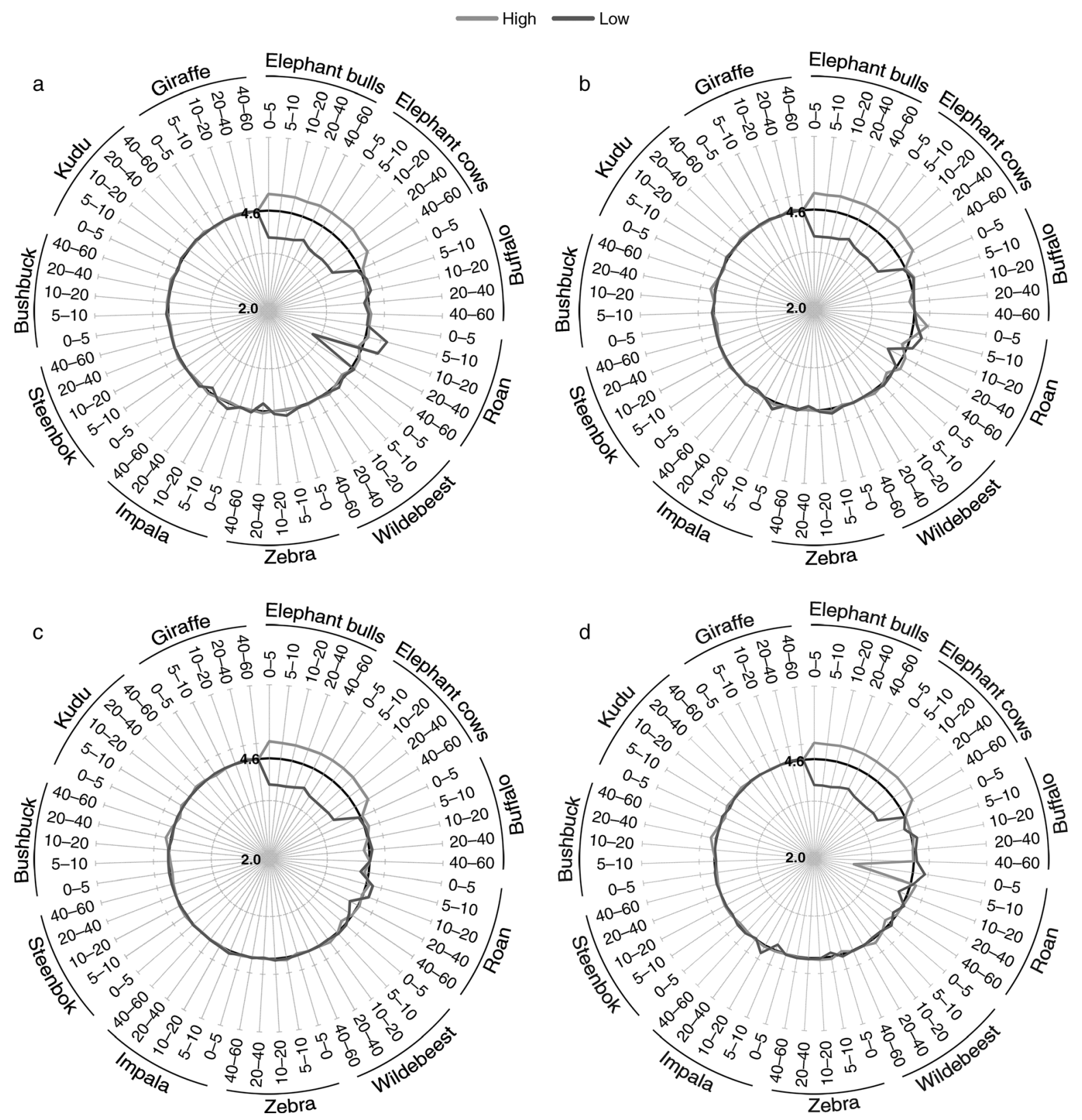

FIG. 4. The change in spatial distributions at distances of $0-5,5-10,10-20,20-40$, and $40-60 \mathrm{~km}$ to perennial rivers in clockwise direction of $(\mathrm{a}-\mathrm{d})$ animal species and $(\mathrm{e}-\mathrm{h})$ plant groups (grass biomass, woody biomass in five size classes) under very dry conditions when (a, e) all WPs are open, (b, f) intermediate WP scenario, (c, g) reduced WP scenario, and (d, h) when all WPs are closed. Differences were standardized by taking the natural logarithm of the percentage of change of high and low elephant densities relative to current elephant densities. See Methods: Water point management scenarios for definitions of these scenarios.

moved closer to rivers than bulls (similar to findings of e.g., Stokke and Du Toit 2002, Smit et al. 2007c). Elephant bulls and cows showed to be less affected by the closure of WPs than most of the other herbivore species, which is supported by other studies (Redfern et al. 2005, Smit et al. 2007a, b, c). Meso-grazer and impala densities increased in the proximity of rivers during drought conditions when WPs were closed, forcing them to move toward rivers. However, densities near rivers increased when water availability reduced, indicating that the negative effects of elephants on available forage became less important in determining the spatial distribution of the meso-mixed feeders and meso-grazers when water became limiting. The meso-browsers, bushbuck and kudu, also showed a redistribution toward rivers when WPs were closed under drought conditions, but giraffe and steenbok appeared unaffected by any changes in water availability, indicating that forage drives their spatial distributions (Redfern 2002, Redfern et al. 2003, Smit et al. 2007a). 

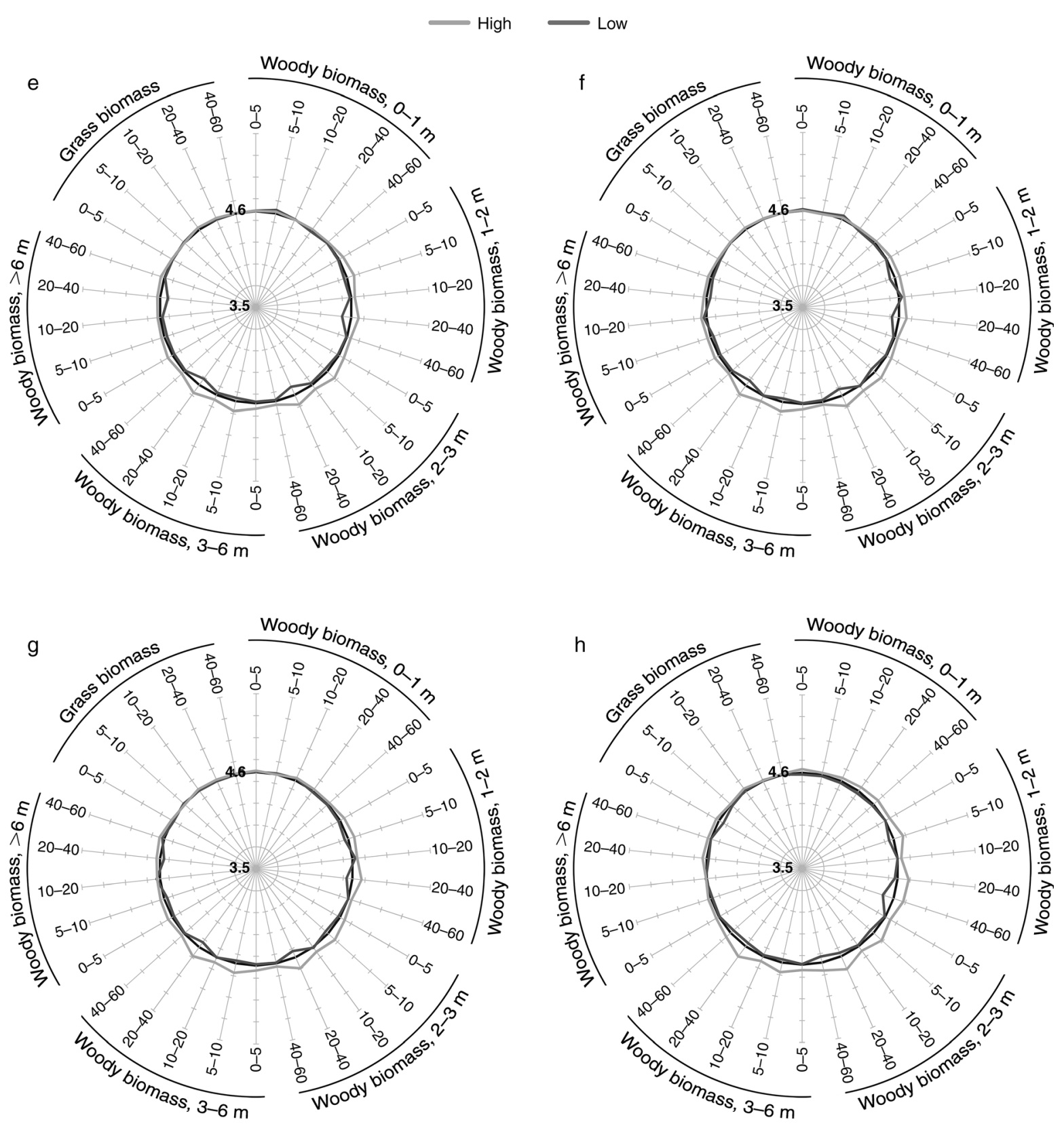

FIG. 4. Continued.

At present, KNP management is planning to close more of the remaining WPs in the park in order to facilitate a return to previous animal distribution patterns, and to allow vegetation to recover and to promote heterogeneity. The results from this modeling exercise suggest, however, that even more extreme measures might be necessary to allow vegetation and animal distribution patterns to return to conditions before the construction of WPs. Note, though, that we did not consider the effects of the closure of WPs on animal densities in this study, whereas it can be expected that closing WPs might affect not only animal distribution patterns but also their densities
(Chamaillé-Jammes et al. 2007b). However, to our knowledge, empirical evidence for effects of WP closure on animal densities is absent.

The indirect management actions that aim to influence the spatial distribution of wildlife are poorly studied compared to the effect of direct actions such as culling (Balfour et al. 2007, Van Aarde et al. 2008). To our knowledge, the results from this study provide new and improved insights into wildlife management by the large-scale and cascading effects of water management in savanna ecosystems. However, SAVANNA and other ecological models are always limited in predicting 
ecosystem changes, and validation of ecological models is, therefore, of great importance. In addition, to account for uncertainty in the model, a sensitivity analysis, to identify the most important parameters of the model and to test the robustness of the results, should be a future research priority. Our results imply that the impacts of the closure of water points may go largely unnoticed until droughts occur, and that longterm effects of intervention strategies, such as closure of water points, should always be investigated at an ecosystem scale.

\section{Literature Cited}

Balfour, D., H. T. Dublin, J. Fennessy, D. Gibson, L. Niskanen, and I. J. Whyte. 2007. Review of options for managing the impacts of locally overabundant African elephants. World Conservation Union (IUCN), Gland, Switzerland.

Biggs, H. C., R. Slotow, B. Scholes, J. Carruthers, R. Van Aarde, G. Kerley, W. Twine, D. Grobler, H. Bertschinger, and C. Grant. 2008. Towards integrated decision-making for elephant management. Pages 537-586 in R. J. Scholes and K. G. Mennell, editors. Elephant management: a scientific assessment for South Africa. Wits University Press, Johannesburg, South Africa.

Bond, W. 1993. Keystone species. Pages 237-253 in E. D. Shultze and H. A. Mooney, editors. Biodiversity and ecosystem function. Springer-verlag, Berlin, Germany.

Boone, R. 2007. Effects of fragmentation on cattle in African savannas under variable precipitation. Landscape Ecology 22:1355-1369.

Boone, R. B., S. B. BurnSilver, P. K. Thornton, J. S. Worden, and K. A. Galvin. 2005. Quantifying declines in livestock due to land subdivision. Rangeland Ecology and Management 58:523-532.

Boone, R. B., M. B. Coughenour, K. A. Galvin, and J. E. Ellis. 2002. Addressing management questions for Ngorongoro Conservation Area, Tanzania, using the Savanna modelling system. African Journal of Ecology 40:138-150.

Boone, R. B., and N. T. Hobbs. 2004. Lines around fragments: effects of fencing on large herbivores. African Journal of Range and Forage Science 21:147-158.

Cameron, E. Z., and J. T. Du Toit. 2007. Winning by a neck: tall giraffes avoid competing with shorter browsers. American Naturalist 169:130-135.

Chamaillé-Jammes, S., M. Valeix, and H. Fritz. $2007 a$. Elephant management: why can't we throw out the babies with the artificial bathwater? Diversity and Distributions 13:663-665.

Chamaillé-Jammes, S., M. Valeix, and H. Fritz. $2007 b$. Managing heterogeneity in elephant distribution: interactions between elephant population density and surface-water availability. Journal of Applied Ecology 44:625-633.

Coughenour, M. B. 1985. Graminoid responses to grazing by large herbivores: adaptations, exaptations, and interacting processes. Annals of the Missouri Botanical Garden 72:852863.

Coughenour, M. B. 1993. The SAVANNA landscape model: documentation and user's guide. Natural Resource Ecology Laboratory, Colorado State University, Fort Collins, Colorado, USA.

de Beer, Y., and R. J. Van Aarde. 2008. Do landscape heterogeneity and water distribution explain aspects of elephant home range in southern Africa's arid savannas? Journal of Arid Environments 72:2017-2025.

de Boer, W. F., and H. H. T. Prins. 1990. Large herbivores that strive mightily but eat and drink as friends. Oecologia $82: 264-274$
De Knegt, H. J., et al. 2011. The spatial scaling of habitat selection by African elephants. Journal of Animal Ecology 80:270-281.

$\mathrm{Du}$ Toit, J. T. 1990. Feeding-height stratification among African browsing ruminants. African Journal of Ecology 28:55-61

Du Toit, J. T., K. H. Rogers, and H. C. Biggs. 2003. The Kruger experience: ecology and management of savanna heterogeneity. Island Press, Washington, D.C., USA.

Dublin, H. T., A. R. E. Sinclair, and J. McGlade. 1990. Elephants and fire as causes of multiple stable states in the Serengeti-Mara woodlands. Journal of Animal Ecology 59:1147-1164.

Ellis, J., and M. Coughenour. 1998. The SAVANNA integrated modelling system: an integrated remote sensing, GIS and spatial simulation modelling approach. Pages $97-106$ in V. R. Squires and A. E. Sidahmed, editors. Drylands: sustainable use of rangelands into the twenty-first century. International Fund for Agricultural Development (IFAD) Technical Reports, Rome, Italy.

Fritz, H., P. Duncan, I. J. Gordon, and A. W. Illius. 2002. Megaherbivores influence trophic guilds structure in African ungulate communities. Oecologia 131:620-625.

Greyling, M. D. 2004. Sex and age related feeding distinctions in the feeding ecology of the African elephant, Loxodonta africana. Dissertation. University of the Witwatersrand, Johannesburg, South Africa.

Harris, G. M., G. J. Russell, R. I. Van Aarde, and S. L. Pimm. 2008. Rules of habitat used by elephants (Loxodonta Africana) in southern Africa: insights for regional management. Oryx 42:66-75.

Haschick, S. L., and G. I. H. Kerley. 1996. Experimentally determined foraging heights of bushbuck (Tragelaphus scriptu)s and boergoats (Copra hircus). South African Journal of Wildlife Research 26:64-65.

Jacobs, S. M., and R. J. Naiman. 2008. Large African herbivores decrease herbaceous plant biomass while increasing plant species richness in a semi-arid savanna toposequence. Journal of Arid Environments 72:891-903.

Kerley, G. I. H., M. Landman, L. Kruger, N. Owen-Smith, D. Balfour, W. F. de Boer, A. Gaylard, K. Lindsay, and R. Slotow. 2008. Effects on elephants on ecosystems and biodiversity. Pages 146-205 in R. J. Scholes and K. G. Mennell, editors. Elephant management: a scientific assessment for South Africa. Wits University Press, Johannesburg, South Africa.

Kiker, G. A. 1998. Development and comparison of Savanna ecosystem models to explore the concept of carrying capacity. Dissertation. Cornell University, Ithaca, New York, USA.

Knapp, A. K., et al. 2012. A test of two mechanisms proposed to optimize grassland aboveground primary productivity in response to grazing. Journal of Plant Ecology 5:357-365.

Kohi, E. M., W. F. de Boer, M. J. S. Peel, R. Slotow, C. van der Waal, I. M. A. Heitkönig, A. Skidmore, and H. H. T. Prins. 2011. African elephants (Loxodonta Africana) amplify browse heterogeneity in African savanna. Biotropica 43:711-721.

Lagendijk, G., B. R. Page, and R. Slotow. 2012. Short-term effects of single species browsing release by different-sized herbivores on Sand Forest vegetation community, South Africa. Biotropica 44:63-72.

Loarie, S. R., R. J. V. Aarde, and S. L. Pimm. 2009. Fences and artificial water affect African savannah elephant movement patterns. Biological Conservation 142:3086-3098.

Ludwig, J. A., M. B. Coughenour, A. C. Liedloff, and R. Dyer. 2001. Modelling the resilience of Australian savanna systems to grazing impacts. Environment International 27:167-172.

Makhabu, S. W. 2005. Resource partitioning within a browsing guild in a key habitat, the Chobe Riverfront, Botswana. Journal of Tropical Ecology 21:641-649. 
Martin, J., S. Chamaillé-Jammes, J. D. Nichols, H. Fritz, J. E. Hines, C. J. Fonnesbeck, D. I. MacKenzie, and L. L. Bailey. 2010. Simultaneous modeling of habitat suitability, occupancy, and relative abundance: African elephants in Zimbabwe. Ecological Applications 20:1173-1182.

Mwakiwa, E., et al. 2013. Optimization of wildlife management in a large game reserve through waterpoints manipulation: a bio-economic analysis. Journal of Environmental Management 114:352-361.

Owen-Smith, N. 1989. Megafaunal extinctions: the conservation message from 11000 years B.P. Conservation Biology 3:405-412.

Redfern, J. V. 2002. Manipulating surface water availability to manage herbivore distributions in the Kruger National Park, South Africa. Dissertation. University of California, Berkley, California, USA.

Redfern, J. V., R. Grant, H. Biggs, and W. M. Getz. 2003. Surface-water constraints on herbivore foraging in the Kruger National Park, South Africa. Ecology 84:2092-2107.

Redfern, J. V., C. C. Grant, A. Gaylard, and W. M. Getz. 2005. Surface water availability and the management of herbivore distributions in an African savanna ecosystem. Journal of Arid Environments 63:406-424.

Ripple, W. J., and R. L. Beschta. 2012. Trophic cascades in Yellowstone: the first 15 years after wolf reintroduction. Biological Conservation 145:205-213.

Shannon, G., M. Thaker, A. Vanak, B. Page, R. Grant, and R. Slotow. 2011. Relative impacts of elephant and fire on large trees in a savanna ecosystem. Ecosystems 14:1372-1381.

Skarpe, C., et al. 2004. The return of the giants: ecological effects of an increasing elephant population. Ambio 33:276282.

Smit, I. P. J. 2011. Resources driving landscape-scale distribution patterns of grazers in an African savanna. Ecography

Smit, I. P. J. 2013. Systems approach towards surface water distribution in Kruger National Park, South Africa. Pachyderm 53:91-96.

Smit, I. P. J., and S. M. Ferreira. 2010. Management intervention affects river-bound spatial dynamics of ele-

Smit, I. P. J., and C. C. Grant. 2009. Managing surface-water in a large semi-arid savanna park: effects on grazer distribution patterns. Journal for Nature Conservation 17:61-71.

Smit, I. P. J., C. C. Grant, and B. J. Devereux. 2007a. Do artificial waterholes influence the way herbivores use the 34:67-74. phants. Biological Conservation 143:2172-2181.

landscape? Herbivore distribution patterns around rivers and artificial surface water sources in a large African savanna park. Biological Conservation 136:85-99.

Smit, I. P. J., C. C. Grant, and I. J. Whyte. 2007b. Elephants and water provision: what are the management links? Diversity and Distributions 13:666-669.

Smit, I. P. J., C. C. Grant, and I. J. Whyte. 2007c. Landscapescale sexual segregation in the dry season: distribution and resource utilization of elephants in Kruger National Park, South Africa. Diversity and Distributions 13:225-236.

Smith, R. K., A. S. Pullin, G. B. Stewart, and W. J. Sutherland. 2010. Effectiveness of predator removal for enhancing bird populations. Conservation Biology 24:820-829.

Stokke, S., and J. T. Du Toit. 2002. Sexual segregation in habitat used by elephants in Chobe National Park, Botswana. African Journal of Ecology 40:360-371.

Thornton, P., R. Fawcett, K. Galvin, R. Boone, J. Hudson, and C. Vogel. 2004. Evaluating management options that use climate forecasts: modelling livestock production systems in the semi-arid zone of South Africa. Climate Research 26:3342.

Valeix, M., H. Fritz, R. Sabatier, F. Murindagomo, D. Cumming, and P. Duncan. 2011. Elephant-induced structural changes in the vegetation and habitat selection by large herbivores in an African savanna. Biological Conservation 144:902-912.

Van Aarde, R. J., et al. 2008. Elephant population biology and ecology. Pages 84-145 in R. J. Scholes and K. G. Mennell, editors. Elephant management: a scientific assessment for South Africa. Wits University Press, Johannesburg, South Africa.

Van Aarde, R. J., and T. P. Jackson. 2007. Megaparks for metapopulations: addressing the causes of locally high elephant numbers in southern Africa. Biological Conservation 134:289-297.

Van De Koppel, J., and H. H. T. Prins. 1998. The importance of herbivore interactions for the dynamics of African savanna woodlands: a hypothesis. Journal of Tropical Ecology 14:565-576.

Van Langevelde, F., et al. 2003. Effects of fire and herbivory on the stability of savanna ecosystems. Ecology 84:337-350.

Wright, R. G. 1999. Wildlife management in the national parks: questions in search of answers. Ecological Applications 9:3036.

\section{Supplemental Material}

Ecological Archives

Appendices A-E are available online: http://dx.doi.org/10.1890/14-0322.1.sm

Data Availability

Data associated with this paper have been deposited in Wageningen UR Library: http://edepot.wur.nl/312397 